\title{
Avaliação termográfica da região do carpo de cavalos Puro Sangue Inglês de corrida jovens em início de treinamento
}

Bianca Pegoraro Vieira, Thasla de Freitas Santi, Fernanda Mendes Barussi, Fernanda Zettel Bastos, Hanna Caroline Prochno, Pedro Vicente Michelotto Jr"

Pontifícia Universidade Católica do Paraná (PUCPR), Curitiba PR, Brasil

*Autor correspondente

e-mail: michelottojunior@yahoo.com.br

\section{Resumo}

Lesões musculoesqueléticas são a principal razão para a interrupção do treinamento de cavalos de corrida, sendo o carpo uma região especialmente acometida. A termografia infravermelha é uma técnica de uso clínico bastante útil para a investigação do sistema locomotor dos cavalos, pois permite detectar alterações superficiais de perfusão sanguínea, podendo indicar processos inflamatórios de forma precoce. A hipótese do presente estudo é que o uso periódico da termografia pode ajudar a entender as alterações musculoesqueléticas que ocorrem em cavalos de corrida e antecipar a observação de alterações antes do agravamento de lesões. Assim, o objetivo do presente estudo, aprovado pelo Comitê de Ética no Uso de Animais PUCPR - 00951A, foi realizar a avaliação da variação térmica da região do carpo de cavalo Puro Sangue Inglês (PSI) de corrida em início de treinamento. Quinzenalmente foram avaliados cavalos da raça PSI de 2 anos de idade no período inicial de treinamento, transcorrido de junho de 2016 a janeiro de 2017. As imagens termográficas coletadas dos membros torácicos vista frontal e palmar, com aproximadamente 1,5 m de distância de cada animal, foram registradas com a Câmera Térmica Flir E50bx e foram avaliadas através do programa Flir Tools, informando a temperatura superficial dos pontos pré-determinados, sendo eles carpo direito e esquerdo. As coletas de dados foram feitas sempre no mesmo horário (entre 6h e 6h30min) com os animais na própria baia, aproximadamente 15 min após a escovação, contidos pelo cabresto. As imagens termográficas obtidas foram analisadas e indicaram aumento significativo das temperaturas dos carpos dos animais durante o estágio de treinamento. Ao se comparar a última avaliação em relação à primeira, a variação no período do estudo foi de um acréscimo de $7,16^{\circ} \mathrm{C}$ na avaliação pela vista dorsal e $7,3^{\circ} \mathrm{C}$ na vista palmar $(\mathrm{P}<0,0001)$. Assim, conclui-se que o acompanhamento dos cavalos de corrida com o uso da termografia infravermelha pode ser muito útil no entendimento da adaptação do sistema 
musculoesquelético ao treinamento. Próximos estudos deverão ser feitos na avaliação do valor preditivo da termografia na antecipação de alterações que possam levar a lesões.

Palavras-chave: Diagnóstico por imagem. Equinos. Termografia infravermelha. 